\title{
Applied Cointegration Analysis in the Mirror of Macroeconomic Theory
}

\author{
Paul Söderlind. Anders Vredin*
}

October 1995

* The authors thank Tor Jacobson, Torsten Persson, Anders Warne, Michael Wickens and two anonymous referees for comments; Tom Cooley for making the solution algorithm for the model available. Financial support from Bank of Sweden Tercentenary Foundation and Jan Wallander Research Foundation is gratefully acknowledged. 


\section{Summary}

Cointegration analyses of macroeconomic time series are often not based on fully specified theoretical models. We use a theoretical model to scrutinize common procedures in applied cointegration analysis. Monte Carlo experiments show that $(i)$ some tests of the cointegration vectors do not work well on series generated by an equilibrium business cycle model; (ii) cointegration restrictions add little in forecasting; (iii) structural VAR models based on weak long run restrictions seem to work well. The main disadvantages of cointegration analysis without strong links to economic theory are that it makes it hard to estimate and interpret the cointegration vectors.(JEL C32, E32.)

Keywords: cointegration, money demand, common trends, equilibrium business cycle model. 


\section{Introduction}

Empirical research about macroeconomic relations has benefited from a rapid development in statistical analysis of non-stationary time series. Statistical tests for the order of integration and cointegration have proven very useful in empirical model building and are now routinely performed. Cointegration restrictions are essential in error-correction, VAR and common trends models.

It seems both intuitively reasonable and consistent with casual observations that macroeconomic variables are tied together in the long run. For example, money, income, and prices do not develop independently over time. Money and real income may behave as random walks individually, but they are driven by common trends, that is, they are cointegrated. Cointegrating relations between $\log$ money, log income, and log prices are, however, not constant. Many authors, among them Engle and Granger (1987), interpret stationary fluctuations in such linear combinations as equilibrium errors, for instance, as excess supplies of money. ${ }^{1}$

The claim that cointegration and equilibrium concepts are closely related is rarely based on fully specified economic models. The interpretation of the short-run movements in cointegrating relations as equilibrium errors implicitly refers to theories about adjustment costs and non-clearing markets, but an explicit connection is almost never demonstrated. This makes it hard to interpret empirical cointegrating relations, and it is sometimes unclear what the analysis has to say about economic behavior.

There are some attempts to establish explicit links between cointegration and economic theory. Campbell (1987) studies cointegration implications of the permanent income hypothesis. King et al. (1991) derive cointegration restric-

\footnotetext{
1 Prices and exchange rates similarly seem to have common trends. Although real exchange rates are not constant, they appear to be stationary and mean-reverting. The short run fluctuations in real exchange rates could similarly be interpreted as equilibrium errors since they correspond to deviations from purchasing power parity. These examples are often, as in Burda and Wyplosz (1993), interpreted as evidence of long run monetary neutrality.
} 
tions between aggregate income, consumption, and investment from a stochastic neoclassical growth model. Ogaki (1992) derives cointegration restrictions from first order conditions of a consumer's optimization problem in order to test Engel's Law. Söderlind (1994) arrives at cointegrating relationships between output in different countries from a stochastic endogenous growth model. ${ }^{2}$

In this paper we use a macroeconomic equilibrium model to scrutinize some common procedures in applied cointegration analysis. We have chosen to put our discussion in the framework of the monetary business cycle model by Cooley and Hansen (1995). In Section 2 we discuss the model's cointegration implications and derive its common trends representation. We pay particular attention to cointegration relations between money, income, prices, and interest rates. This is motivated by the fact that studies of money demand often have been used to illustrate new methods for analysis of cointegrated multivariate time series. In Section 3 we perform Monte Carlo studies based on a modified version of the business cycle model. The simulations are used to shed light on three common applications of VAR models with cointegration restrictions: testing of economic hypotheses (related to money demand, in particular), forecasting, and policy analysis (of monetary policy shocks, in particular). Our conclusions are presented in Section 4 .

\section{Cointegration in Equilibrium Business Cycle Models}

\subsection{A Monetary Business Cycle Model}

The workhorse models in modern "new classical" business cycle studies are the growth models due to Solow and Ramsey. In the Solow growth model with an exogenous savings rate, the economy converges towards a steady state with a constant capital-output ratio. If there is no technological progress, dimin-

\footnotetext{
${ }^{2}$ Wickens (1993) and Bårdsen and Fisher (1993) have a somewhat more traditional econometric perspective. They discuss the relation between cointegration and structural/reduced form models at a conceptual level, without reference to explicit economic models.
} 
ishing returns to capital will make the levels of capital stock and output (per capita) constant in steady state. With an exogenously given rate of technological change, output and capital grow at the rate of technical progress. Even with endogenous savings, as in the Ramsey model, the capital stock grows at the rate of technical change, just like consumption. The steady state ratio of capital and consumption is determined by the preference and technology parameters.

With stochastic growth, exogenous or endogenous, similar models produce stationary capital-output and consumption-output ratios, as in King et al. (1991) or Mellander, Vredin, and Warne (1992). While the cointegrating vectors contain no particular information about preferences or technology, the stationary fluctuations in the cointegrating relations depend on "deep" parameters. In the following we will express this message more formally. We will base our discussion on a modified version of Cooley and Hansen's (1995) monetary equilibrium business cycle model.

This model is a fairly standard quarterly real business cycle model, with some additional features. A stochastic money supply interacts with a cash-in-advance transaction technology, and nominal wage contracts, to create temporary real effects of money supply shocks. The key equations, slightly modified, are listed below. We use the convention that lower case letters denote values for a certain household, whereas upper case letters denote aggregates.

Utility function: $\quad \mathrm{E}_{0} \sum_{t=0}^{\infty} \beta^{t}\left[\alpha \ln c_{1 t}+(1-\alpha) \ln c_{2 t}-\gamma h_{t}\right]$.

Real budget constraint: $\quad c_{1 t}+c_{2 t}+k_{t+1}+\frac{m_{t+1}}{P_{t}}=W_{t} h_{t}+\left(r_{t}-\delta+1\right) k_{t}+\frac{m_{t}}{P_{t}}+\frac{\Delta M_{t}}{P_{t}}$.

Cash-in-advance constraint: $P_{t} c_{1 t}=m_{t}+\Delta M_{t}$, or in aggregate: $P_{t} C_{1 t}=M_{t}$.

Production function: $\quad Y_{t}=K_{t}^{\theta}\left(Z_{t} H_{t}\right)^{1-\theta}$.

Capital accumulation: $\quad K_{t+1}=(1-\delta) K_{t}+I_{t}$.

Nominal wage contract: $\quad \ln \left(P_{t} W_{t}\right)=\ln (1-\theta)+\theta\left(\ln K_{t}-\ln \mathrm{E}_{t-1} H_{t}\right)+$ $\mathrm{E}_{t-1}\left((1-\theta) \ln Z_{t}+\ln P_{t}\right)$.

Money supply: $\quad \Delta \ln M_{t+1}=\eta \Delta \ln M_{t}+\xi_{t+1}$.

Log productivity: $\quad \ln Z_{t+1}=\rho \ln Z_{t}+\epsilon_{t+1}$.

Parameter values: $\quad \theta=0.4, \delta=0.019, \beta=0.989, \gamma=2.53, \alpha=0.84$,

$\rho=1, \epsilon_{t+1} \sim N\left(0,1.36 \times 10^{-4}\right)$,

$\eta=0.49, \xi_{t+1} \sim N\left(7.65 \times 10^{-3}, 7.92 \times 10^{-5}\right)$.

Most of the notation and parameter values are standard. ${ }^{3}$ Private consump-

3 The notation is: capital stock $\left(K_{t}\right)$, money holdings $\left(M_{t}\right)$, price level $\left(P_{t}\right)$, wage rate 
tion consists of a "cash good," $c_{1 t}$, and a "credit good," $c_{2 t}$. The cash-in-advance constraint requires the nominal value of purchases of the cash good, $P_{t} c_{1 t}$, to be (less or) equal to the money stock brought over from $t-1, m_{t}$, plus lump sum transfers from the government received in cash at the beginning of $t, \Delta M_{t}$. In this paper we use $\rho=1$, that is, a random walk in productivity, whereas Cooley and Hansen (1995) used $\rho=0.95$. The lognormal distribution of $\xi_{t+1}$ is here approximated with a normal distribution, which simplifies the derivation of the nominal interest rate considerably. We will also report results from two other parameterizations of the model: one with higher autocorrelation in money growth $(\eta=0.8$ instead of 0.49$)$, and one with lower autocorrelation $(\eta=0.2)$. The reason is that we want to allow for varying degree of persistence in the simulations. In both cases the variance of the shocks to money growth $\left(\xi_{t+1}\right)$ is set to make the long run response to a shock of one standard deviation the same as in (1).

The equilibrium concept is fairly involved, reflecting the complex nature of stochastic dynamic rational expectations models. Loosely speaking, a household picks consumption, labor supply, money holdings, and investment to maximize expected utility, taking into account not only the stochastic processes and transition equations, but also expectations about what other agents do and the resulting prices, wages, and rental rates. Firms maximize profits each period by hiring labor and capital. The equilibrium outcome is a set of decision rules, which relate aggregate variables to the current state of the economy.

Solving an approximation of the model results in a set of linear decision rules. Ignoring unimportant constants, these rules are

$$
\left[\begin{array}{c}
\ln K_{t+1} \\
\ln H_{t} \\
\ln P_{t}
\end{array}\right]=\left[\begin{array}{lll}
\psi_{K M} & \psi_{K \xi} & \psi_{K K} \\
\psi_{H M} & \psi_{H \xi} & \psi_{H K} \\
\psi_{P M} & \psi_{P \xi} & \psi_{P K}
\end{array}\right]\left[\begin{array}{c}
\Delta \ln M_{t} \\
\xi_{t} \\
\ln K_{t}-\ln Z_{t}
\end{array}\right]+\left[\begin{array}{c}
\ln Z_{t} \\
0 \\
\ln M_{t}-\ln Z_{t}
\end{array}\right]
$$

In the standard case with moderate autocorrelation in money growth $(\eta=0.49$

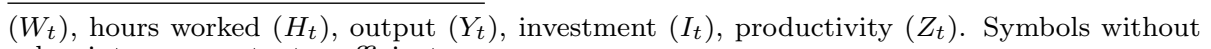
subscripts are constant coefficients. 
as in (1)) the numerical values are

$$
\left[\begin{array}{ccc}
\psi_{K M} & \psi_{K \xi} & \psi_{K K} \\
\psi_{H M} & \psi_{H \xi} & \psi_{H K} \\
\psi_{P M} & \psi_{P \xi} & \psi_{P K}
\end{array}\right]=\left[\begin{array}{ccc}
0.0194 & 0.1527 & 0.9572 \\
-0.0562 & 3.4969 & -0.4646 \\
0.4696 & -0.0933 & -0.5856
\end{array}\right] .
$$

Setting $\eta$ to 0.2 or 0.8 gives other values. ${ }^{4}$ It is straightforward to calculate other equilibrium variables by combining (1) and (2). For instance, log output is obtained by substituting for $\ln K_{t}$ and $\ln H_{t}$ in the $\log$ production function.

The model has two assets, real capital and nominal money. The implicit return on a synthetic nominal "bond", $R_{t}$, can be determined from an Euler equation for bond holdings. Using the property of joint conditional normality and the equilibrium condition in the money market we have ${ }^{5}$

$$
\begin{aligned}
\ln R_{t} & =\mathrm{E}_{t} \Delta \ln P_{t+1}+\mathrm{E}_{t} \Delta \ln C_{1 t+1}-\ln \beta-\operatorname{Var}_{t}\left(\Delta \ln P_{t+1}+\Delta \ln C_{1 t+1}\right) / 2 \\
& =\eta \Delta \ln M_{t}-\ln \beta+\mathrm{E} \xi_{t}-\sigma_{\xi}^{2} / 2
\end{aligned}
$$

The first line in (4) is a Fisher type relation where the nominal interest rate equals expected inflation (first term) plus the real interest rate, and the second term uses the equilibrium on the money market.

\subsection{A Common Trends Representation}

Combining (1), (2), and (4) gives the moving average representation of $\ln Y_{t}$, $\ln P_{t}, \ln M_{t}$, and $\ln R_{t}$. This can be written as a "common trends model"

$$
\begin{aligned}
& {\left[\begin{array}{c}
\ln Y_{t} \\
\ln P_{t} \\
\ln M_{t} \\
\ln R_{t}
\end{array}\right]=\left[\begin{array}{l}
0 \\
1 \\
1 \\
0
\end{array}\right] t * \frac{\mathrm{E} \xi_{t}}{1-\eta}+\left[\begin{array}{cc}
0 & 1 \\
1 & -1 \\
1 & 0 \\
0 & 0
\end{array}\right]\left[\begin{array}{c}
\mu_{t} \\
\ln Z_{t}
\end{array}\right]+C(\mathrm{~L})\left[\begin{array}{l}
\xi_{t} \\
\epsilon_{t}
\end{array}\right]} \\
& { }^{4} \text { With } \eta=0.2 / 0.8 \text { we get }\left[\begin{array}{ccc}
0.0086 / 0.0160 & 0.1226 / 0.1953 & 0.9572 / 0.9572 \\
-0.0111 /-0.3967 & 2.8082 / 4.4712 & -0.4646 /-0.4646 \\
0.1938 / 0.7491 & -0.0750 /-0.1193 & -0.5856 /-0.5856
\end{array}\right] \text {. } \\
& 5 \text { We would have to resort to numerical integration if } \Delta \ln M_{t+1} \text { was lognormally dis- }
\end{aligned}
$$


The first term in (5) is a deterministic trend due to the drift in money supply.

The second term in (5) contains the common trends, which are usually defined as independent random walks

$$
\left[\begin{array}{c}
\mu_{t} \\
\ln Z_{t}
\end{array}\right]=\left[\begin{array}{c}
\mu_{t-1} \\
\ln Z_{t-1}
\end{array}\right]+\left[\begin{array}{cc}
\frac{1}{1-\eta} & 0 \\
0 & 1
\end{array}\right]\left[\begin{array}{c}
\xi_{t} \\
\epsilon_{t}
\end{array}\right]
$$

The third term in (5) is the stationary part, where $C(\mathrm{~L})$ is a $4 \times 2$ matrix polynomial

$C(\mathrm{~L})=\left[\begin{array}{cc}\frac{(1-\theta) \psi_{H M}}{1-\eta \mathrm{L}}+(1-\theta) \psi_{H \xi}+\left(\frac{\psi_{K M}}{1-\eta \mathrm{L}}+\psi_{K \xi}\right) \frac{\left(\theta+(1-\theta) \psi_{H K}\right) \mathrm{L}}{1-\psi_{K K} \mathrm{~L}} & -\frac{\theta+(1-\theta) \psi_{H K}}{1-\psi_{K K} \mathrm{~L}} \\ \frac{\psi_{P M}}{1-\eta \mathrm{L}}+\psi_{P \xi}+\left(\frac{\psi_{K M}}{1-\eta \mathrm{L}}+\psi_{K \xi}\right) \frac{\psi_{P K} \mathrm{~L}}{1-\psi_{K K} \mathrm{~L}}-\frac{\eta /(1-\eta)}{1-\eta \mathrm{L}} & -\frac{\psi_{P K}}{1-\psi_{K K} \mathrm{~L}} \\ -\frac{\eta /(1-\eta)}{1-\eta \mathrm{L}} & 0 \\ \frac{\eta}{1-\eta \mathrm{L}} & 0\end{array}\right]$

The main features of the model can be glimpsed from the impulse response functions in Figures 1a-b. The figures trace out the response to a shock of one standard deviation in the model with $\eta=0.49$. In Figure 1a, we see that a typical shock to money supply growth leads to (i) a cumulative increase in money supply, since money growth rates are autocorrelated; (ii) a response of $\ln P_{t}$ which is very similar to that of $\ln M_{t}$; (iii) an increase in the interest rate, mainly driven by the Fisher effect (inflation expectations); (iv) a onequarter increase in output because the inflation surprise combined with oneperiod nominal wage contracts. In Figure 1b, a typical productivity shock gives (i) a persistent jump in output; (ii) a negative and cumulating effect on the price level (the cash-in-advance constraint binds, but consumption increases initially less than proportionally to productivity due to investments); (iii) no effects on the money supply (exogenous) or nominal interest rate (due to the logarithmic utility function). The effect of increasing the autocorrelation in money growth from 0.49 to 0.8 is shown in Figures $1 c$ - $d$ : the initial response to a standardized money supply shock is lower since these shocks are smaller (lower standard deviation), but the effect builds up over a longer period to give the same asymptotic value (by construction); the effect of a productivity shock is almost unchanged. 
Empirical analyses of common trends models usually assume that the common stochastic trends are unobservable random walks. The relevant exogenous trends in our equilibrium model are the productivity level $\left(\ln Z_{t}\right)$ and the money stock $\left(\ln M_{t}\right)$. While the productivity level defines a trend in the common trends representation (5)-(7), log money stock must be split into a deterministic drift, $t * \mathrm{E} \xi_{t}$, a stationary $\operatorname{AR}(1),-\eta /((1-\eta)(1-\eta \mathrm{L})) \xi_{t}$, and finally a random walk, $\mu_{t}$, to fit into the common trends representation. ${ }^{6}$ The equilibrium model shows that it does not always make sense to extract a "nominal trend" in this way from an estimated common trends model.

The model in (5)-(7) has four variables, two stochastic trends, and therefore two stationary relations. ${ }^{7}$ One such relation is simply the nominal interest rate, $\ln R_{t}$, which has no trend since the growth rate of money is stationary.

The cash-in-advance constraint implies that $\ln C_{1 t}-\ln P_{t}-\ln M_{t}$ is constant. Since the conditions of King, Plosser, and Rebelo (1988) are satisfied (constant returns to scale and a unit elasticity of substitution between goods and leisure is enough) the model has a balanced growth path. Along that path, income and substitution effects cancel so hours worked are stationary, and consumption of both goods are stationary shares of output. For instance, the budget restriction can be combined with (5)-(7) to show that $\ln C_{1 t}-\ln Y_{t}$ is stationary. Combining this with the cash-in-advance constraint tells us that $\log$ velocity $\left(\ln V_{t}\right)$

$$
\ln V_{t}=\ln Y_{t}+\ln P_{t}-\ln M_{t}
$$

is also stationary. A cointegrating vector for the four variables in (5) is therefore $[1,1,-1,0]$. This vector cancels both the deterministic drift and the stochastic trends.

The previous results illustrate a common property of models with balanced growth paths: stochastic trends combined with balanced growth paths give trivial cointegrating vectors. The interesting information about economic behavior

\footnotetext{
${ }^{6}$ The deterministic trend is due to $\mathrm{E} \xi_{t} \neq 0$. The decomposition is $\ln M_{t}=t * \mathrm{E} \xi_{t} /(1-\eta)$ $+\mu_{t}-\frac{\eta}{1-\eta} \frac{\xi_{t}-\mathrm{E} \xi_{t}}{1-\eta \mathrm{L}}$, where $\mu_{t}=\frac{1}{1-\eta} \frac{\xi_{t}-\mathrm{E} \xi_{t}}{1-\mathrm{L}}$.

7 The duality between cointegration and common trends is studied in Stock and Watson (1988).
} 
(technology and preferences) is revealed by the fluctuations in the cointegrating relations as seen in (5)-(7); the fluctuations around the common trends depend on the deep parameters either directly $(\eta$ and $\theta)$, or indirectly via the decision rules $\left(\psi_{i j}\right)$. We have demonstrated this with a neoclassical model, but the paradigm of balanced growth paths extends far beyond this particular class of models.

This result stands in sharp contrast to most empirical cointegration studies, which tend to be atheoretical with a Keynesian flavor. ${ }^{8}$ These studies usually concentrate on interpreting the cointegrating vectors, often assumed to reflect long run demand or supply functions, and view the fluctuations in the cointegrating relations as fairly uninteresting equilibrium errors. The (equilibrium) model we use show that this is not the only possible interpretation. To further emphasize this point, we will now use the theoretical model to look more closely on one specific macroeconomic application of cointegration analysis.

\subsection{Cointegration and Money Demand}

Studies of models for money, income, prices, and interest rates are common in the empirical cointegration literature. The purpose has sometimes been to test hypotheses about money demand, as in Hafer and Jansen (1991) and Hoffman and Rasche (1991); sometimes mainly to illustrate the properties of cointegration tests, as in Johansen and Juselius (1990), and Stock and Watson (1993). The analyses have typically been based on a vector error correction model

$$
\sum_{i=0}^{p} \Gamma_{i} \Delta x_{t-i}+\Pi x_{t-1}=\varepsilon_{t}
$$

where $x_{t}^{\prime}=\left[\ln Y_{t}, \ln P_{t}, \ln M_{t}, \ln R_{t}\right]$. The hypothesis of $r$ cointegrating vectors ( $n-r=4-r$ common trends) implies that the matrix $\Pi$ has rank $r$, and may

\footnotetext{
8 The label "Keynesian" is perhaps unfair to Keynes (1923) who claimed "In the long run we are all dead. Economists set themselves too easy, to useless a task if in tempestuous seasons they can only tell us that when the storm is long past the ocean is flat again." This was a critique of assuming that the quantity equation $P C=M$ holds in the short run, but he also wrote "Now 'in the long run' this is probably true." One may perhaps conjecture that Keynes would not have liked the model we use, but that he would have been willing to estimate an error correction model with the long run restriction that the quantity equation holds.
} 
be written as

$$
\Pi=\tilde{\alpha} \tilde{\beta}^{\prime}
$$

where the columns of the $n \times r$ matrix $\tilde{\beta}$ contain the cointegrating vectors. The $r$ cointegrating relations $\tilde{\beta}^{\prime} x_{t}$ are often interpreted as equilibrium errors, and the $n \times r$ matrix $\tilde{\alpha}$ contains error correction parameters which show how fast the variables change in response to a disequilibrium.

In the absence of a fully specified economic model, it is not easy to interpret the estimates of $r, \tilde{\beta}$, and $\tilde{\alpha}$. As we understand it, the finding of one, and only one, cointegrating vector for $x_{t}^{\prime}=\left[\ln Y_{t}, \ln P_{t}, \ln M_{t}, \ln R_{t}\right]$ has been used to support an interpretation of that vector as a long run money demand relation and of the associated cointegrating relation as a measure of excess money. An estimate of $r>1$ is considered to make the search for a money demand function harder, perhaps because any linear combination of the cointegrating vectors could qualify as money demand relation. ${ }^{9}$

Money holdings in the equilibrium model (1) have to obey the cash-inadvance constraint $M_{t}=P_{t} C_{1 t}$. This can be rewritten as a traditional money demand equation by first using the first order conditions from the optimization problem to find the trade-off between cash and credit goods (the nominal interest rate is the relevant relative price), and then use a log-linear approximation of the resource constraint (adjusts output for investments, which are credit goods) to get the equilibrium relation

$$
\ln M_{t}-\ln P_{t}-\ln Y_{t}=-\alpha \ln R_{1 t}+\delta \kappa \ln Y_{t}+(1-\delta) \kappa \ln K_{t}-\kappa \ln K_{t+1}
$$

where $\alpha$ is the relative weight on cash goods in the utility function, $\delta$ is the depreciation rate (see $(1)$ ), and $\kappa$ is the ratio of capital stock to consumption in steady state. This equation relates real money holdings to output, the nominal interest rate and (essentially) investment. The left hand side of (11) is $-\ln V_{t}$, and it is stationary since the weights on $\ln Y_{t}, \ln K_{t}$, and $\ln K_{t+1}$ sum to zero so

\footnotetext{
9 To be fair, the money demand interpretation has also been based on the findings (i) if $\tilde{\beta}_{1}=\left[\tilde{\beta}_{11}, \tilde{\beta}_{12}, 1, \tilde{\beta}_{14}\right]$ denotes the first normalized cointegrating vector, then it is often the case that $\tilde{\beta}_{11} \approx \tilde{\beta}_{12} \approx-1$, and $0<\tilde{\beta}_{14}<1$; (ii) the error correction parameters $\tilde{\alpha}$ have economically interpretable signs and values.
} 
the common trend component $\left(\ln Z_{t}\right)$ vanishes, and the nominal interest rate is stationary. In fact, any combination of $\ln V_{t}$ and $\ln R_{t}$ is stationary, since $\ln V_{t}$ and $\ln R_{t}$ are stationary themselves.

The interpretation of (11) as a money demand equation is not without problems. First, the capital-consumption ratio $\kappa$ depends on the average money growth rate $\left(\mathrm{E} \xi_{t} /(1-\eta)\right.$; see $\left.(1)\right)$. To understand this, let us imagine two economies with different rates of growth in the money supply. The higher this growth rate is, the higher is the inflation rate, that is, the higher is the tax on money holdings. The agents in the economy with the higher inflation tax will to a larger extent substitute consumption of the credit good and/or leisure for consumption of the cash good. ${ }^{10}$ Second, suppose we dropped the $\ln K_{t}$ and $\ln K_{t+1}$ terms, but allowed for lags of the interest rate and output, as is often done in applied money demand studies. The coefficients on these lags would then depend on, among other things, the money supply parameter $\eta$ (since the decision rules in (2) and (3) do).

This discussion leads us to the following conclusions. First, while a stationary relation between $\ln Y_{t}, \ln P_{t}, \ln M_{t}$, and $\ln R_{t}$ can be derived from the equilibrium model, it is misleading to interpret this relation as reflecting a traditional money demand equation. It is an equilibrium relation which depends on the household's maximization problem as well as the money supply process. Second, the fluctuations in the cointegration relation (here, velocity) trace out an equilibrium relation, and should not be interpreted as equilibrium errors. Third, the (short and long run) equilibrium relation between $\ln V_{t}$ and $\ln R_{t}$ cannot be found by cointegration analysis, since $\ln V_{t}$ and $\ln R_{t}$ are both stationary. ${ }^{11}$

This discussion about money demand complements the general discussion

\footnotetext{
${ }^{10}$ See Cooley and Hansen (1989) for a thorough analysis of this meachanism in an economy with only cash goods.

${ }^{11}$ It is conceivable that a model where $\ln V_{t}$ and $\ln R_{t}$ are both $I(1)$ and cointegrated can be constructed, for instance, by assuming that the money supply process is characterized by $\eta=1$ instead of $\eta=0.49$ as in (1). For the same reasons as those given above, it could still be misleading to interpret the cointegration relation as a money demand relation. Furthermore, to our knowledge, it has not been shown beyond doubt that velocity is nonstationary (see e.g. Hafer and Jansen (1991)), or argued that this would be a necessary condition for a cointegration relation between $\ln Y_{t}, \ln P_{t}, \ln M_{t}$, and $\ln R_{t}$ to qualify as a money demand relation.
} 
above about cointegration in the equilibrium model. It provides a specific example of why one should be careful when interpreting cointegration relations.

\section{Testing and Interpreting Cointegrated VAR Systems}

The discussion above illustrates how hard it can be to formulate meaningful hypotheses for the cointegration analysis without strong links to economic theory. In this section we present some Monte Carlo experiments based on the theoretical model in Section 2. The purpose of the simulations is to complement the general arguments above with some quantifications of the usefulness of macroeconomic theory for common applications of cointegration analysis. Three types of applications, hypothesis testing, forecasting, and policy analysis, are discussed in Sections 3.2-3.4. In Section 3.1 we augment the theoretical model with measurement errors, which provides a simple way to generate multivariate time series with a non-singular covariance structure.

The small sample properties of cointegration tests and the usefulness of cointegration restrictions for forecasting are important issues in applied cointegration analysis, and have indeed been addressed in earlier research. One difference between our exercises in Sections 3.2 and 3.3 and those of, for instance Gonzalo (1994), Cheung and Lai (1993), and Clements and Hendry (1995), is that our simulations are based on a fully specified economic model - "strong" theory in the sense of Cooley and Dwyer (1995) - which (some) economists claim is useful for understanding macroeconomic fluctuations. This means that we are studying the properties of cointegration tests when applied on a data generating process derived from economic theory, which typically will involve MA components. Another issue is whether VAR models, with or without cointegration restrictions - "weak" theory in the sense of Cooley and Dwyer, can be

used to estimate the economy's response to various disturbances. Section 3.4 is devoted to a comparison of impulse response functions derived from "strong" 
and "weak" theory.

\subsection{Simulation and Estimation Setup}

The model is hard to take to data since there are only two basic stochastic processes, but four observed series. We therefore add two independent AR(1) measurement errors to output and money supply, with autocorrelations of 0.3 and 0.2 respectively. The standard deviations of the shocks are set to give a $5 \%$ increase in the (unconditional) standard deviations of output growth and money growth. This model is simulated to generate 3000 samples of 200 quarters. ${ }^{12}$

The model has non-trivial moving average components, which is a common feature of time series representations derived from optimizing models. We follow the tradition in applied cointegration analysis by assuming that a low-order VAR system can provide a reasonable approximation. Some, but far from all, of our results will be driven by this misspecification. The catch is that this misspecification would not be picked up by standard misspecification tests (see below), so these kinds of errors could very well be made in practical work. To get a better understanding of the importance of the MA terms, we also report estimates based on simulations of a VAR representation of the data. This representation is generated in a very simple way: an error correction model (with the true cointegrating vectors imposed) is estimated with 3 lags on a sample of 40000 observations from the true model; then the estimated VAR model is simulated in the same way as the true model to generate 3000 samples.

The tests we study can be sensitive to the choice of lag order. We therefore present most results for three different ways of picking the lag order of the empirical error correction model: the Hannan-Quinn criterion (HQ), Akaike's criterion (AIC), and AIC with two extra lags. The fitted models do not fail multivariate portmanteau diagnostic tests for serial correlation and non-normality considerably more often than expected when using the $5 \%$ critical values from the

\footnotetext{
12 The simulations are made in the GAUSS programming language, using the random number generator RDND initialized with RNDSEED 123456789 at the first (of 3000) simulation. Each sample of 450 periods is initialized with zeros for lagged shocks and variables, and the first 250 periods are then discarded.
} 
asymptotic distributions. ${ }^{13}$ There is no relation between the results from the diagnostic tests and the results of the tests applied below. It seems safe to claim that the subsequent results are not due to simple misspecification errors which would be discovered by commonly applied diagnostic tests.

The key parameter for the degree of persistence in the equilibrium model is the autocorrelation of money supply growth, $\eta$. This is somewhat troubling since it is not entirely clear which monetary aggregate (M1, M2, or ...) that $\ln M_{t}$ in the model corresponds to. We will therefore report results from three different model versions with values of $\eta$ of $0.2,0.49$, and 0.8 .

Most applied cointegration studies on macro data use quarterly data for two to four decades. We will therefore report results from both a relatively short sample (100 quarters) and a relatively long sample (200 quarters).

\subsection{Cointegration Tests}

One of the first steps in applied cointegration analysis is to determine the cointegration rank $(r)$, that is, the number of independent cointegrating vectors. This is a crucial step because the subsequent analysis is conditioned on $r$. The properties of Johansen's (1991) trace test (it can be shown that the maximum eigenvalue test gives very similar results) for the cointegration rank are illustrated in Table I, which shows the relative frequency that a particular cointegration rank $(r)$ is chosen. The table gives results for sample lengths $(T)$ of 100 and 200, and for the models with an autocorrelation of money supply $(\eta)$ of $0.2,0.49$, and 0.8. In each case, the lag order is taken from AIC. Values for the simulations of the approximate VAR representations are given in parentheses. The trace test in Table I behaves a lot better in the longer sample: the true value $r=2$ (ln $V_{t}$ and $\ln R_{t}$ are stationary) is picked in around $60 \%$ of the simulations when $T=100$ but in $80 \%$ of the cases when $T=200$. The improvement is entirely

\footnotetext{
13 For instance, the results for $\eta=0.49$ are as follows. The preferred lag order for $T=100$ is usually 1 for HQ, and 1-3 for AIC. For $T=200$ it is usually $1-2$ for HQ, and $2-4$ for AIC. The rejection rates for the hypothesis of no autocorrelation (up to the $10^{t h}$ order) at for $T=100$ $(200)$ are $3 \%(8 \%)$, using AIC. The corresponding figures for the hypothesis of normality are $7 \%$ (8\%). See, for instance, Lütkepohl (1993) for a description of these diagnostic tests.
} 
due to a reduction in the frequency of underestimated $r$. Also, at $T=200$, the three models generate very similar results. The difference between the estimates based on simulations of the true model and those based on simulations of the VAR approximation is negligible.

\begin{tabular}{|c|ccc|ccc|}
\hline & \multicolumn{3}{|c|}{$T=100$} & \multicolumn{3}{c|}{$T=200$} \\
& \multicolumn{3}{|c}{$\eta$} & & \\
$r$ & 0.2 & 0.49 & 0.8 & 0.2 & 0.49 & 0.8 \\
\hline 0 & $0(0)$ & $0(0)$ & $0(0)$ & $0(0)$ & $0(0)$ & $0(0)$ \\
1 & $21(28)$ & $19(22)$ & $11(13)$ & $1(2)$ & $0(0)$ & $0(0)$ \\
2 (true) & $61(53)$ & $61(56)$ & $59(59)$ & $80(81)$ & $78(80)$ & $75(77)$ \\
3 & $10(9)$ & $11(11)$ & $14(14)$ & $11(10)$ & $12(11)$ & $14(12)$ \\
4 & $8(10)$ & $10(11)$ & $16(15)$ & $8(8)$ & $9(8)$ & $12(11)$ \\
\hline
\end{tabular}

Figures in parentheses are from simulations of approximate VAR representation. Lag order from Akaike (AIC). Critical values from Johansen and Juselius (1990), Table A1. $\mathrm{H}_{0}: r \leq r_{0}, r_{0}=0,1,2,3$.

Drifts, which cancel in the cointegrating relations, are allowed.

Table I: Frequencies (in \%) of preferred cointegration rank in Johansen's Trace test, for various $\eta$.

Table II focuses on the model with $\eta=0.49$, but looks at the effects of different ways of choosing the lag order (HQ,AIC, AIC+2), as well at a small sample correction of the test statistics $\left(\mathrm{AIC}_{s s}\right.$, indicating that the lag order is from AIC). This correction scales down the test statistic by ( $T$-number of estimated parameters) $/ T$, as discussed by Reinsel-Ahn (1988) and Cheung and Lai (1993). The idea behind this correction has been to adjust for the tendency to overestimate the cointegration rank. Table II shows that a shorter lag length (HQ) gives less underestimation of $r$, especially in the short sample. Cheung and Lai (1993) also find that a short lag order often lead to a higher estimate of $r$, but this is not good in their model since it has a true null of $r=0$. It is interesting to note that the small sample correction makes things even worse when $T=100$, since it increases the degree of underestimation of $r$ more than it decreases the degree of overestimation.

The next step in applied cointegration analysis is often to test economic restrictions on the cointegrating vectors. We use the likelihood ratio test to study 


\begin{tabular}{|c|cccc|cccc|}
\hline & \multicolumn{4}{|c|}{$\underline{T=100}$} & \multicolumn{4}{c|}{$\underline{T=200}$} \\
& & & & & \\
$r$ & $\mathrm{HQ}$ & $\mathrm{AIC}$ & $\mathrm{AIC}+2$ & $\mathrm{AIC}_{S S}$ & $\mathrm{HQ}$ & $\mathrm{AIC}$ & $\mathrm{AIC}+2$ & $\mathrm{AIC}_{S S}$ \\
\hline 0 & $0(0)$ & $0(0)$ & $0(0)$ & $0(0)$ & $0(0)$ & $0(0)$ & $0(0)$ & $0(0)$ \\
1 & $14(21)$ & $19(22)$ & $31(35)$ & $37(41)$ & $0(0)$ & $0(0)$ & $1(4)$ & $1(2)$ \\
2 (true) & $69(62)$ & $61(56)$ & $47(43)$ & $52(47)$ & $83(82)$ & $78(80)$ & $77(77)$ & $84(84)$ \\
3 & $9(9)$ & $11(11)$ & $10(9)$ & $6(5)$ & $11(10)$ & $12(11)$ & $12(10)$ & $9(8)$ \\
4 & $8(8)$ & $10(11)$ & $12(12)$ & $5(5)$ & $6(7)$ & $9(8)$ & $10(9)$ & $6(6)$ \\
\hline
\end{tabular}

HQ: lag order from Hannan-Quinn; AIC: lag order from Akaike; AIC+2: lag order from

Akaike plus 2; $\mathrm{AIC}_{S S}$ : lag order from Akaike with small sample correction of test statistics. See Table I for further information.

Table II: Frequencies (in \%) of preferred cointegration rank in Johansen's Trace test, $\eta=0.49$.

the (true) hypotheses that $[1,1,-1,0]$ and/or $[0,0,0,1]$ are in the cointegration space, that is, that $\ln V_{t}$ and/or $\ln R_{t}$ are stationary $\left(\mathcal{H}_{5}\right.$ hypotheses in the language of Johansen-Juselius (1992)), and that the real money stock $\ln \left(M_{t} / P_{t}\right)$ enters the cointegrating relations, that is, the coefficients of prices and money are equal with opposite sign (a $\mathcal{H}_{4}$ hypothesis). These tests are conditional on a maintained cointegration rank.

\begin{tabular}{|c|c|c|c|c|c|c|}
\hline \multirow[b]{2}{*}{ Test of: } & \multicolumn{3}{|c|}{$\frac{T=100}{\eta}$} & \multicolumn{3}{|c|}{$\underline{T=200}$} \\
\hline & 0.2 & 0.49 & 0.8 & 0.2 & 0.49 & 0.8 \\
\hline $\ln R_{t} \sim I(0)$ & $2(8)$ & $2(8)$ & $2(10)$ & $0(7)$ & $0(7)$ & $0(6)$ \\
\hline $\ln V_{t} \sim I(0)$ & $41(27)$ & $35(26)$ & $19(23)$ & $16(11)$ & $11(10)$ & $2(8)$ \\
\hline $\ln R_{t} \& \ln V_{t} \sim I(0)$ & $28(23)$ & $22(24)$ & $11(22)$ & $7(10)$ & $4(10)$ & $1(9)$ \\
\hline Only $\ln M / P$ matters & $20(19)$ & $17(19)$ & $11(19)$ & $6(10)$ & $4(10)$ & $1(8)$ \\
\hline
\end{tabular}

See Table I for descriptions.

Table III: Rejection probabilities (in \%) at the $5 \%$ level for Johansen's LR test of cointegration space, condition al on $r=2$.

The simulation results, conditional on $r=2$, for various $\eta$ (lag order by AIC) are shown in Table III. The estimates based on simulations of the approximate VAR representation give similar results across the models, and the rejection 
rates decrease towards $5 \%$ as the sample gets longer. ${ }^{14}$ In contrast, the estimates based on the simulations of the true model simulations behave rather strange. The rejection rates of stationarity of $\ln R_{t}$ are much lower than the asymptotic $5 \%$, in spite of the fact that $\ln R_{t}$ is actually an $\mathrm{AR}(1)$; the MA components in other series apparently spill over. The rejection rates of stationarity of $\ln V_{t}$, which is well approximated by an $\operatorname{ARMA}(1,1)$, differ widely across models. The rejection rate decreases with the degree of persistence in money supply $(\eta)$. The joint test of stationarity of $\ln R_{t}$ and $\ln V_{t}$ seems to be an average of the individual tests. Finally, the test of proportionality, which is of another nature and has another distribution, behaves reasonably well, irrespective of whether the data is generated by the true model or the VAR representation.

\begin{tabular}{|l|cccc|cccc|}
\hline & \multicolumn{5}{|c|}{$\underline{T=100}$} & \multicolumn{4}{c|}{$\underline{T=200}$} \\
Test of: & \multicolumn{9}{|c}{} & & & \\
& $\mathrm{HQ}$ & $\mathrm{AIC}$ & $\mathrm{AIC}+2$ & $\mathrm{AIC}_{S S}$ & $\mathrm{HQ}$ & $\mathrm{AIC}$ & $\mathrm{AIC}+2$ & $\mathrm{AIC}_{S S}$ \\
\hline $\ln R_{t} \sim I(0)$ & $1(2)$ & $2(8)$ & $3(14)$ & $1(5)$ & $0(2)$ & $0(7)$ & $0(9)$ & $0(5)$ \\
$\ln V_{t} \sim I(0)$ & $45(27)$ & $35(26)$ & $25(27)$ & $29(20)$ & $27(13)$ & $11(10)$ & $6(12)$ & $9(9)$ \\
$\ln R_{t} \& \ln V_{t} \sim I(0)$ & $30(18)$ & $22(24)$ & $17(32)$ & $16(17)$ & $13(7)$ & $4(10)$ & $2(14)$ & $3(8)$ \\
Only $\ln M / P$ matters & $20(14)$ & $17(19)$ & $15(26)$ & $17(19)$ & $10(7)$ & $4(10)$ & $3(14)$ & $4(10)$ \\
\hline
\end{tabular}

See Table II for descriptions.

Table IV: Rejection probabilities (in \%) at the $5 \%$ level for Johansen's LR test of cointegration space, condition al on $r=2$.

Table IV shows how the tests of the cointegration space are affected by the choice of lag order and by a small sample correction. For the simulations based on the approximate VAR representation the best results are obtained with a short lag order (HQ). The results are adversely affected by adding more lags, at least in the short sample. This is somewhat counter to the results by Gonzalo (1994), who shows that too few lags affects the small sample distribution of the cointegrating vectors much more than too many lags. The estimates based on data generated by the exact model give results more in line with Gonzalo (1994): a short lag order (HQ) leads to high rejection rates. The small sample

\footnotetext{
14 Results from a VAR model showing (slow) monotone convergence to the asymptotic 5\% have been presented by Jacobsson, Vredin, and Warne (1993).
} 
correction works fairly well for both the shorter and longer samples.

\begin{tabular}{|c|ccc|ccc|}
\hline & \multicolumn{3}{|c|}{$T=100$} & \multicolumn{3}{c|}{$T=200$} \\
& \multicolumn{3}{|c}{$\eta^{2}$} & \multicolumn{3}{c|}{} \\
& 0.2 & 0.49 & 0.8 & 0.2 & 0.49 & 0.8 \\
\hline $\ln P$ & $1.21(1.08)$ & $1.19(1.07)$ & $1.11(1.04)$ & $1.08(1.02)$ & $1.06(1.02)$ & $1.03(1.01)$ \\
$\ln M$ & $-1.20(-1.07)$ & $-1.18(-1.06)$ & $-1.13(-1.05)$ & $-1.07(-1.02)$ & $-1.06(-1.01)$ & $-1.03(-1.01)$ \\
\hline
\end{tabular}

Table V: Median of normalized cointegration vector, for various $\eta$.

These rejections of the cointegration vectors seem to be partly due to a small sample bias in one of the cointegrating vectors. To illustrate this, we transform the estimated cointegration vectors by dividing the first vector with its fourth element. This produces estimates which are very close to the theoretical $[0,0,0,1]$. We then transform the second cointegrating vector by subtracting the fourth element times the first vector times (gives zero as the new fourth element), and then normalizing by dividing by the first element.

Table $V$ shows the medians of the two unrestricted elements in this vector, which should be compared with the theoretical values of 1 and -1 from the vector $[1,1,-1,0]$. There is an upward bias of the coefficients on $\ln P_{t}$ and $\ln M_{t}$, and the bias is almost the same for both variables. This accounts for the high rejection rates of stationarity of $\ln V_{t}$ and the reasonable rejection rates of proportionality of prices and money in Table IV. In terms of the common trends representation (5), the bias means that the productivity trend $\ln Z_{t}$ affects $\ln P_{t}$ less than $\ln Y_{t}$. We conjecture that the prolonged response of prices to a productivity shock (see Figures $1 \mathrm{~b}$ and $1 \mathrm{~d}$ ) is not well captured in small samples.

Our overall impression of the results for Johansen's test of the cointegration rank and test of the cointegration space is that they are not without problems when trying to nail down the long-run properties of the data generating process, especially in short samples and when there are important MA components. 


\subsection{Forecasting Performance}

As a second exercise, we examine if cointegration restrictions are important for forecasting. We compare the results from a restricted error correction model (the true cointegrating vectors are imposed) with an unrestricted VAR and a "naive" forecast where output, prices, and money are treated as random walks, and the interest rate and the velocity as constants.

We consider out-of-sample forecasts from models estimated on the first 100/192 quarters for each of the 3000 simulated samples when $\eta=0.8$ and the lag order is from AIC. Table VI shows the percentage gain in the mean squared error (MSE) from using the restricted model rather than a naive forecast. ${ }^{15}$ For the non-stationary variables, the results are given for both the level (first entry in each cell) and the growth rates (second entry). In some cases, the naive forecast outperforms the estimated model; it can be seen from Table VII that these are the cases when the true model implies very little forecastability. The estimated model does relatively better in the longer sample, and relatively worse for the growth rates.

\begin{tabular}{|c|c|c|c|c|c|c|c|c|c|c|}
\hline \multirow{2}{*}{$\begin{array}{l}\text { Fore- } \\
\text { cast } \\
\text { hori- } \\
\text { zon }\end{array}$} & \multicolumn{5}{|c|}{$T=100$} & \multicolumn{5}{|c|}{$T=192$} \\
\hline & $\ln Y$ & $\ln P$ & $\ln M$ & $\ln R$ & $\ln V$ & $\ln Y$ & $\ln P$ & $\ln M$ & $\ln R$ & $\ln V$ \\
\hline 1 & $19 / 19$ & $7 / 7$ & $51 / 51$ & 56 & 26 & $21 / 21$ & $16 / 16$ & $57 / 57$ & 62 & 30 \\
\hline 4 & $-10 /-6$ & $7 /-4$ & $32 / 4$ & 6 & 15 & $2 /-3$ & $16 / 1$ & $39 / 7$ & 11 & 25 \\
\hline 8 & $-20 /-2$ & $0 /-6$ & $12 /-9$ & -2 & 5 & $-5 / 0$ & $9 /-2$ & $21 /-3$ & -1 & 20 \\
\hline
\end{tabular}

The second entry in the cells are for growth rates.

Table VI: Percentage gain in MSE of restricted ECM relative to "naive" forecast, at $\eta=0.8$.

Table VIII shows that the restricted ECM does somewhat better than the unrestricted VAR, but that the difference is small for the growth rates and for the short-run forecasts. It can be shown that the results are almost identical

\footnotetext{
${ }^{15}$ A weakness of the MSE is that it does not incorprorate the covariances of the forecasting errors, see Clements and Hendry (1993). Here, the correlation matrices of the forecast errors are very similar for the restricted and unrestricted models.
} 


\begin{tabular}{|l|ccccc|}
\hline $\begin{array}{l}\text { Forecasting } \\
\text { horizon }\end{array}$ & $\Delta \ln Y_{t}$ & $\Delta \ln P_{t}$ & $\Delta \ln M_{t}$ & $\ln R$ & $\ln V$ \\
\hline 1 quarter & 0.30 & 0.22 & 0.62 & 0.64 & 0.67 \\
4 quarters & 0 & 0.07 & 0.15 & 0.17 & 0.51 \\
8 quarters & 0 & 0.02 & 0.03 & 0.03 & 0.36 \\
\hline
\end{tabular}

Table VII: Theoretical forecast $R^{2}$ for the model, at $\eta=0.8$.

when the approximate VAR representation is used to generate the data instead of the true model. The model versions with less autocorrelation in money growth $(\eta=0.2$ and 0.49$)$, and therefore less predictability, show qualitatively similar results.

\begin{tabular}{|c|c|c|c|c|c|c|c|c|c|c|}
\hline \multirow{2}{*}{$\begin{array}{l}\text { Fore- } \\
\text { cast } \\
\text { hori- } \\
\text { zon }\end{array}$} & \multicolumn{5}{|c|}{$\underline{T=100}$} & \multicolumn{5}{|c|}{$T=192$} \\
\hline & $\ln Y$ & $\ln P$ & $\ln M$ & $\ln R$ & $\ln V$ & $\ln Y$ & $\ln P$ & $\ln M$ & $\ln R$ & $\ln V$ \\
\hline 1 & $7 / 7$ & $9 / 9$ & $14 / 14$ & 7 & 7 & $3 / 3$ & $4 / 4$ & $7 / 7$ & 3 & 2 \\
\hline 4 & $17 / 4$ & $22 / 15$ & $26 / 24$ & 13 & 12 & $10 / 2$ & $14 / 9$ & $15 / 13$ & 8 & 5 \\
\hline 8 & $23 / 2$ & $30 / 17$ & $32 / 23$ & 9 & 12 & $19 / 2$ & $23 / 15$ & $23 / 19$ & 11 & 8 \\
\hline
\end{tabular}

Table VIII: Percentage gain in MSE of restricted ECM relative to unrestricted VAR, at $\eta=0.8$.

Like Engle and Yoo (1987) we find some evidence the unrestricted model works relatively well at short forecasting horizons. The results for the longer sample and for the growth rates are in line with those of Clements and Hendry (1995).

\subsection{Structural VAR Systems}

To estimate the dynamic effects on output from shocks to money supply and technology, some researchers have advocated the use of so called structural VAR models (for instance, Blanchard and Quah (1989) and King et. al. (1991)). While the original VAR approach launched by Sims (1980) is usually labelled "atheoretical," structural VAR models are based on some prior information 
about the cointegration space, so that an estimated error correction model can be rewritten as a common trends model. Tests for cointegration, like those analysed in Section 3.2, are thus essential ingredients in structural VAR analyses. Identification of structural VAR models is achieved by imposing just enough restrictions so that the shocks and their long run effects may be given economic interpretations. In the terminology of Cooley and Dwyer (1995), structural VAR analysis relies on "weak theory," since it uses only a subset of the theoretical restrictions implied by "strong" (equilibrium) business cycle theory.

Structural VAR analyses are based on the assumption that the common stochastic trends which drive macroeconomic time series are unobservable random walks, for instance to technology and money supply. As pointed out in Section 2.2, this assumption is only partly consistent with the equilibrium business cycle model used in this paper. As a final exercise, we will examine whether "weak theory" nevertheless can be effective in tracing the responses to the underlying shocks. ${ }^{16}$

We impose two common stochastic trends ( $r=2$, which is true) on each of the 3000 estimates from the Johansen method. One restriction on the long run effects of the two stochastic trends in enough to identify the common trends model here (see the discussion in Mellander, Vredin, and Warne (1992) and in Quah (1994)). We use the (true) restriction that one of the permanent shocks (money supply shock) has zero long run effects on output.

Figure 2a illustrates the estimated impulse response function for $\ln Y_{t}$ based on samples of 200 quarters from the model with $\eta=0.49$. The thick solid line is the true response to a shock of one standard deviation to money supply $\left(\xi_{t}\right)$ and the thick dashed line is the true response to a shock of one standard deviation to technology $\left(\epsilon_{t}\right)$. The thin lines are the $5^{t h}$ and $95^{t h}$ percentiles of the 3000 estimates. The estimates are fairly well located: both the short-lived effect of a money supply surprise and the immediate adjustment to a new productivity level

\footnotetext{
16 Nason and Cogley (1994) study the mean impulse response functions from simulations of several monetary RBC models. Their objective is to compare with the results for quarterly U.S. data, while our objective is to see if the estimation/identification procedure generates impulse response functions which are similar to the true model. Koop, Pesaran, and Potter (1995) discuss how impulse response functions may be defined for non-linear models.
} 
are captured. However, there is a slight bias in the size technology effect, and the confidence interval is wide. The restriction of the long-run effect of a money supply shock seems to bite quickly. We conjecture that the underestimated technology effect is related to the bias in the cointegrating vectors. It can be shown that these confidence bands, apart from the first quarters and from the bias discussed above and, look very similar to the asymptotic confidence intervals often reported in applied work. The asymptotic confidence intervals are narrower for the first 4-6 quarters. Figure $2 b$ shows the corresponding results for $\ln P_{t}$, which also look quite good. It can also be shown that we get the same type of results in a shorter sample, or with the model versions with $\eta=0.2$ and $\eta=0.8$, and also with the simulations of the approximate VAR representation.

Faust and Leeper (1995) argue that long-run restrictions are highly unreliable in any finite sample, unless we can (correctly) restrict the way short-run dynamics are linked to long-run effects, for instance, if the data generating process happens to be a low-order VAR system. In the model we use, we really cannot do that since it has an infinite VAR order due to the MA terms. The evidence in Figures 2.a-b suggest that this critique, while correct in principle, does not seem to be devastating in the type of data generating process implied monetary equilibrium business cycle models.

\section{Conclusions}

Macro economic series do not drift apart for too long; they seem to be driven by the same trends. The development of time series analysis tells us that there is potentially a lot to gain, in a statistical sense, from taking into account these common stochastic trends. Not surprisingly, the last few years have witnessed a flood of cointegration studies of various parts of the economy.

In applications of cointegration analysis, estimated cointegration relations are often interpreted as reflecting equilibrium relations, and the fluctuations in the cointegration relations are viewed as indications of disequilibria. Empirical analyses often focus on the long run (cointegration) relations, while the short 
run fluctuations are regarded as fairly uninteresting. One reason for this way of looking at the data might be that the empirical analyses lack clear connections to well specified economic theory.

In many cases, applied cointegration analysis could rely on stochastic growth models. We have chosen to base our discussion on one particular model, namely Cooley and Hansen's (1995) monetary equilibrium business cycle model. This model has one real stochastic trend (productivity), and one monetary stochastic trend (money supply). This model shares one important feature with most growth models: it generates balanced growth paths where the consumption ratio and labor supply are stationary.

While cointegration analysis needs to be based on stochastic growth models, these models often imply trivial cointegrating vectors. One immediate conclusion is that applied cointegration analysis should take one of the following two routes. First, it could test the predictions of models where the balanced growth path is imposed. Second and alternatively, it could possibly be used to refute the whole class of models with balanced growth paths by persuasively demonstrating that the cointegration restrictions do not hold. This is indeed a hard task, and we face a dilemma if it succeeds: we then need to develop a new class of stochastic growth models before we can give economic interpretations of the statistical results.

The equilibrium business cycle model we use shows that cointegration relations may contain no direct information about economic behavior, but that such information may be deduced from short run fluctuations (which practitioners often disregard). Our analysis of the cointegration properties of this model leads us to question the interpretation of a long run relation between money, income, the price level, and the interest rate as a money demand function.

We use simulations of the model to examine if simple economic restrictions can significantly improve the performance of statistical methods, as long as one uses the kind of samples sizes that are available to macro economists. We show three things. First, tests of the cointegrating space have a lot to gain from imposing the number of common trends. For practical work, the implication is 
that cointegration hypotheses and tests should be based on fully specified economic models, even when only some of the cointegration relations are of interest. Second, the precision of forecasts is not particularly improved by imposing the correct cointegrating vectors, especially not for short forecasting horizons. Third, structural interpretations of cointegrated VAR systems based on long run restrictions can replicate the impulse responses of the underlying economic model. In this type of exercises, it is essential that economic theory is used to determine the number of cointegrating relations (and stochastic trends), but good results can be obtained even if the exact properties of these relations are not known.

Our results suggest that the main disadvantages of cointegration analysis without strong links to economic theory are that it makes interpretation of the cointegrating vectors a treacherous exercise, and that it is hard to estimate the correct number of cointegrating vectors (and therefore the number of common trends). When it comes to forecasting, there is not much to gain from knowing the cointegrating vectors rather than estimating them, provided the main focus is on short run forecasts.

The purpose of this paper has not been to suggest that equilibrium models are more useful than disequilibrium models, or that most applied cointegration analyses have been misleading. For one thing, equilibrium business cycle models do not capture all important stylized facts about the fluctuations around the trends (see for instance Söderlind (1994)). It may well be that characteristic features of these fluctuations have been detected in applied cointegration analyses. Our main point is that these analyses need to be interpreted with stronger links with economic theory. We believe that this message is not controversial, but neither do we think that it is trivial. It is the abundance of rather atheoretical applied cointegration analyses that has been the motivation for this study.

\section{References}

[1] Burda, M., and C. Wyplosz (1993), Macroeconomics - a European Text, Oxford University Press. 
[2] Bårdsen, G., and P.G. Fisher (1993), "The importance of being structured," Discussion Paper 2/93, Norwegian School of Economics and Business Administration.

[3] Blanchard, O.J., and D. Quah (1989), "The Dynamic Effects of Aggregate Demand and Supply Disturbances," American Economic Review, 79, 655673.

[4] Campbell, J.Y. (1987), "Does Saving Anticipate Declining Labor Income? An Alternative Test of the Permanent Income Hypothesis," Econometrica, 55, 1249-1273.

[5] Cheung, Y-W., and K.S. Lai (1993), "Finite-Sample Sizes of Johansen's Likelihood Ratio Tests for Cointegration," Oxford Bullentin of Economics and Statistics, 55, 313-328.

[6] Clements, M.P., and D.F. Hendry (1993), "On the Limitations of Comparing Mean Square Forecast Errors," Journal of Forecasting, 12, 617-37.

[7] Clements, M.P., and D.F. Hendry (1995), "Forecasting in Cointegrated Systems," Journal of Applied Econometrics, 10, 127-146.

[8] Cooley, T.F., and M. Dwyer (1995), "Business Cycle Analysis without much Theory: A Look at Structural VARs," mimeo, University of Rochester.

[9] Cooley, T.F., and G.D. Hansen (1989), "The Inflation Tax in a Real Business Cycle Model," The American Economic Review, 79, 733-748.

[10] Cooley, T.F., and G.D. Hansen (1995), "Money and the Business Cycle," in T.F. Cooley (ed.), Frontiers of Business Cycle Research, Princeton University Press.

[11] Engle, R.F., and C.W.J. Granger (1987), "Co-integration and Error Correction: Representation, Estimation, and Testing," Econometrica, 55, 251276.

[12] Engle, R.F., and B.S. Yoo (1987), "Forecasting and Testing in CoIntegrated Systems," Journal of Econometrics, 35, 143-159.

[13] Faust, J., and E.M. Leeper (1995), "When Do Long-Run Identifying Restrictions Give Reliable Results," mimeo, Federal Reserve Board.

[14] Gonzalo, J. (1994), "Five Alternative Methods of Estimating Long-run Equilibrium Relationships," Journal of Econometrics, 60, 203-233.

[15] Hafer, R.W., and D.W. Jansen (1991), "The Demand for Money in the United States: Evidence from Cointegration Tests," Journal of Money, Credit, and Banking, 23, 155-168.

[16] Hoffman, D.L., and R.H. Rasche (1991), "Long-run Income and Interest Elasticities of Money Demand in the United States," The Review of Economics and Statistics, 73, 665-674.

[17] Jacobson, T., A. Vredin, and A. Warne (1993), "Are Real Wages and Unemployment Related," IIES Seminar Paper No. 559. 
[18] Johansen, S. (1991), "Estimation and Hypothesis Testing of Cointegration Vectors in Gaussian Vector Autoregressive Models," Econometrica, 59, 1551-1580.

[19] Johansen, S., and K. Juselius (1990), "Maximum Likelihood Estimation and Inference of Cointegration - with Applications to the Demand for Money," Oxford Bullentin of Economics and Statistics, 52, 169-210.

[20] Johansen, S., and K. Juselius (1992), "Testing Structural Hypotheses in a Multivariate Cointegration Analysis of the PPP and the UIP for UK," Journal of Econometrics, 53, 211-244.

[21] Keynes, J.M. (1923), A Tract on Monetary Reform, MacMillan.

[22] King, R.G., C.I. Plosser, and S.T. Rebelo (1988), "Production, Growth and Business Cycles: I. The Basic Neoclassical Model," Journal of Monetary Economics, 21, 195-232.

[23] King, R.G., C.I. Plosser, J.H. Stock, and M.W. Watson (1991), "Stochastic Trends and Economic Fluctuations," American Economic Review, 81, 819840.

[24] Koop, G., M.H. Pesaran, and S.M. Potter (1995), "Impulse Response Analysis in Non-linear Multivariate Models," Journal of Econometrics, forthcoming.

[25] Lütkepohl, H. (1993), Introduction to Multiple Time Series Analysis, Springer-Verlag.

[26] Mellander, E., A. Vredin, and A. Warne (1992), "Stochastic Trends and Economic Fluctuations in a Small Open Economy," Journal of Applied Econometrics, 7, 369-394.

[27] Nason, J.M., and T. Cogley (1994), "Testing the Implications of LongRun Neutrality for Monetary Business Cycle Models," Journal of Applied Econometrics, 9, S37-S70.

[28] Ogaki, M. (1992), "Engel's Law and Cointegration," Journal of Political Economy, 100, 1027-1046.

[29] Quah, D. (1994), "Comment," in Measuring and Interpreting Business Cycles, FIEF Studies in Labor Markets anad Economic Policy, Oxford University Press.

[30] Reinsel, G.C., and S.K. Ahn (1988), "Asymptotic Properties of the Likelihood Ratio Test for Cointegration in the Non-Stationary Vector AR Model," Technical Report, Department of Statistics, University of Wisconsin.

[31] Sims, C. (1980), "Macroeconomics and Reality," Econometrica, 48, 1-48.

[32] Söderlind, P. (1994), "International Spillovers in an Endogenous Growth Model," Empirical Economics, 19, 501-515.

[33] Söderlind, P. (1994), "Cyclical Properties of a Real Business Cycle Model," Journal of Applied Econometrics, 9, S113-S122. 
[34] Stock, J.H., and M.W. Watson (1988), "Testing for Common Trends," Journal of the American Statistical Association, 83, 1097-1107.

[35] Stock, J.H., and M.W. Watson (1993), "A Simple Estimator of Cointegrating Vectors in Higher Order Integrated Systems," Econometrica, 61, 783-820.

[36] Wickens, M. (1993), "Interpreting Cointegrating Vectors and Common Stochastic Trends," Discussion Paper No. DP 14-93, Center for Economic Forecasting, London Business School. 
Money supply shock, $\eta=0.49$

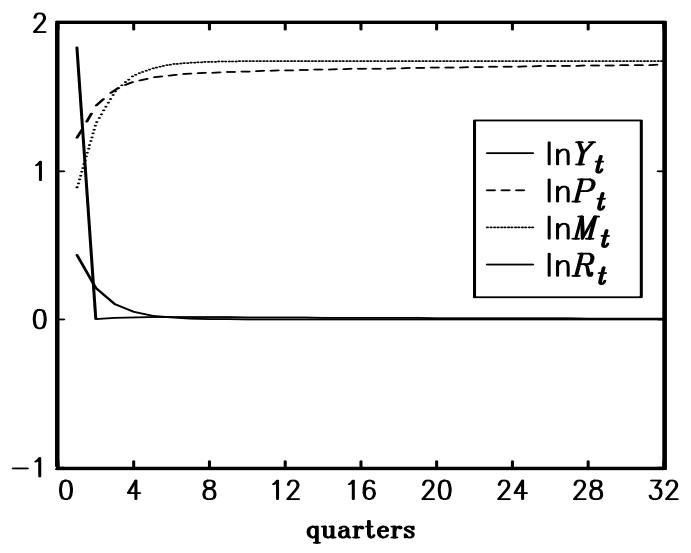

Money supply shock, $\eta=0.8$

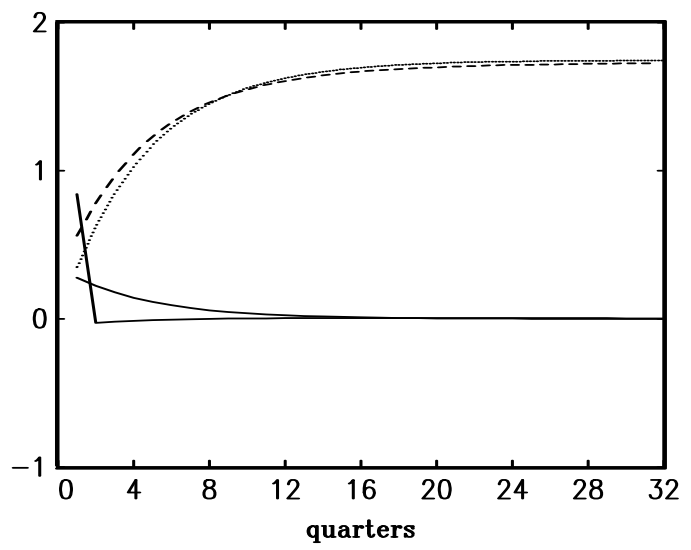

Productivity shock, $\eta=0.49$

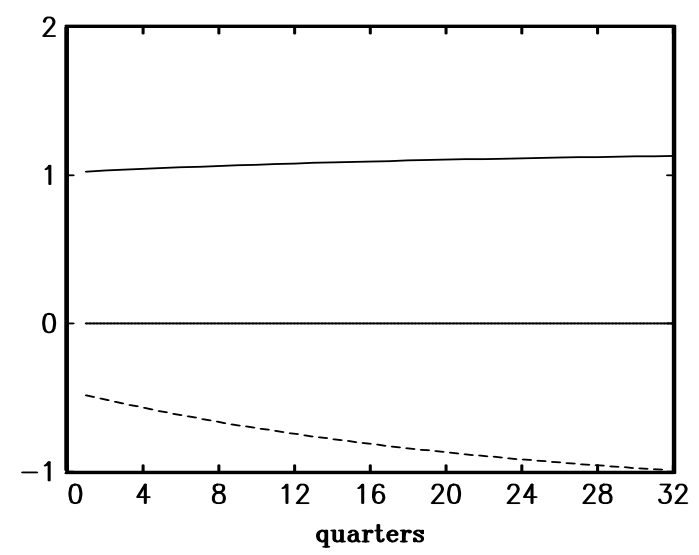

Productivity shock, $\eta=0.8$

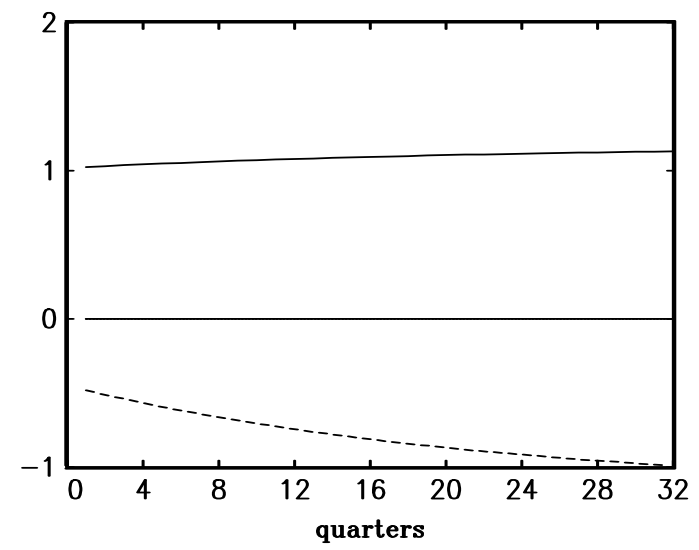

Figure Legends

Figure 1: Impulse response functions for two model versions.

Figure 2: Theoretical impulse response function and estimated confidence bands. 
True DGP and Johansen estimates, $\ln Y_{t}$

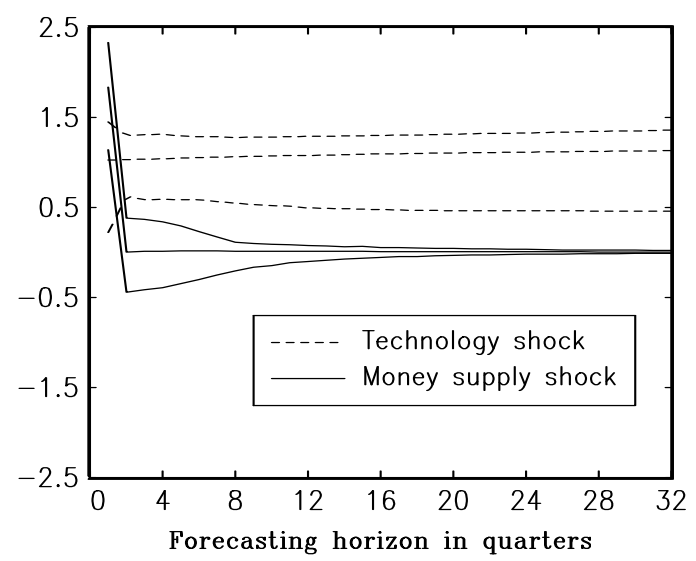

True DGP and Johansen estimates, $\ln P_{t}$

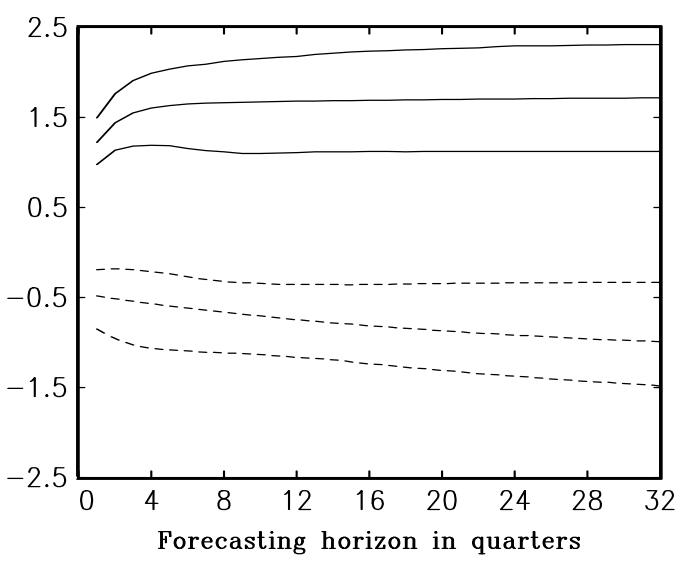

